\title{
OPTIMALISASI PENGELOLAAN KEARSIPAN MELALUI ARSIP-E DI DIREKTORAT JENDERAL GURU DAN TENAGA KEPENDIDIKAN
}

\section{THE OPTIMALIZATION OF ARCHIVE MANAGEMENT WITH E- ARCHIVE IN DIRECTORATE GENERAL OF TEACHERS AND EDUCATION PERSONNEL}

\author{
Soesilo \\ Email: soesms@yahoo.co.id
}

\begin{abstract}
ABSTRAK
Inti masalah yang dikaji adalah bagaimana optimalisasi pengelolaan arsip dengan menggunakan arsip-e di lingkungan Direktorat Jenderal Guru dan Tenaga Kependidikan. Fokus kajian adalah penerapan proyek perubahan untuk tata kelola arsip secara elektronik untuk mencapai tujuan secara efektif dan efisien. Proyek perubahan ini dilakukan melalui enam tahapan, yaitu persiapan perencanaan, pengorganisasian, koordinasi dengan stakeholder, pelaksanaan, evaluasi, dan pembuatan laporan. Proyek tersebut dilaksanakan mulai dari 20 September - 13 November 2016. Dalam pelaksanaan proyek, tentunya tidak terlepas dari dukungan para pihak yang terlibat seperti stakeholder, baik internal maupun eksternal. Keterlibatan pihak stakeholder perlu dinilai dan dianalisis kekuatan pengaruhnya. Metode analisis yang digunakan adalah analisis SWOT. Selama pelaksanaan proyek perubahan, ada beberapa kendala yang dihadapi. Namun, dengan menggunakan suatu strategi, maka kendala tersebut dapat diatasi dengan baik. Dengan adanya proyek perubahan ini, setiap pihak yang terlibat bisa meningkatkan pemahamannya mengenai kearsipan secara elektronik.
\end{abstract}

Kata Kunci: optimalisasi kearsipan, pengelolaan kearsipan, arsip-e.

\section{ABSTRACT}

The core problem investigated in this project is about the optimization of archive management with E-Archive in the milieu of Directorate General of Teachers and Education Personnel. It focuses on the utilization of transformation project for electronic archiving in order to achieve proposed goals effectively and efficiently. The transformation project was conducted in six stages; planning preparation, organization, coordination with stakeholder, execution, evaluation, and reporting. The project was put into action from September 20 to November 13 in 2016. During the project, relevant parties, such as internal and external stakeholder, had offered their supports. The influence of stakeholder involvement should be taken into account and analyzed further. Method of analysis used in the project was SWOT analysis. Throughout the project, challenges had arisen. Regardless, the challenges had been handled thoroughly. With this transformation project, every relevant 
party is able to enhance their understanding of electronic archive or EArchive.

Keywords: archive optimization, archive management, e-archive

\section{PENDAHULUAN}

Informasi telah menjadi kebutuhan mutlak bagi berbagai jenis organisasi, baik pemerintah maupun bisnis pada era globalisasi ekonomi dan pasar bebas yang semakin kompetitif seperti sekarang ini. Dalam kondisi lingkungan yang penuh dengan persaingan, kinerja organisasi bergantung pada seberapa jauh kemampuannya dalam menyelaraskan diri dengan lingkungan stratejik secara kreatif. Hal ini seiring dengan pendapat (Latif \& Pratama, 2008) yang menyatakan Kemajuan teknologi informasi saat ini sudah berkembang begitu pesat, serta memberikan pengaruh besar terhadap berbagai aspek kehidupan, mulai dari lapisan masyarakat baik individu, organisasi, maupun instansi lainnya yang juga tergerak untuk maju dan menggunakannya.

Sebagai salah satu sumber informasi terekam, arsip mempunyai fungsi dan peran yang sangat penting untuk mendukung manajemen modern organisasi pemerintah dan bisnis hal ini sejalan dengan pernyataan (Sutirman, 2015) yaitu bahwa Arsip merupakan salah satu sumber informasi yang penting bagi suatu organisasi. Oleh karenanya, arsip harus dikelola dalam suatu sistem secara konseptual dan terpadu melalui cara yang profesional. Perkembangan zaman yang ditandai dengan penerapan teknologi informasi dan komunikasi menuntut pengelolaan system kearsipan pada suatu lembaga harus mengikuti perkembangan teknologi informasi dan komunikasi (Effendhie, 1993).

Masalah yang sering dihadapi oleh banyak organisasi di dalam mengelola arsip adalah masih terbatasnya SDM yang profesional dalam mengelola arsip dan penerapan sistem kearsipan yang disesuaikan dengan kemajuan teknologi informasi. Pengaruh globalisasi terutama di bidang teknologi informasi menuntut Akselerasi dalam pengelolaan kearsipan. Pengelolaan kearsipan yang tidak bisa mengikuti kemajuan Teknologi informasi akan menjadi penghambat kemajuan suatu instansi. Untuk menghindari berbagai permasalahan yang mungkin mungkin muncul ke depan maka perlu dibingkai dengan peraturan legal mengenai transaksi elektronik (RI, 2008).

Pengelolaan arsip elektronik secara praktis akan mempergunakan media internet. Penggunaan media internet yang prinsipnya informasi bersifat terbuka. Untuk mengatur dan melindungi dampak keterbukaan informasi maka harus dilindungi sebagaimana diatur oleh undang-undang (RI 2008). Termasuk di dalamnya adalah terkait dengan perlindungan terhadap transaksi elektronik. (Undang Undang No.11, 2008). Peningkatan pengelolaan yang profesional terhadap arsip merupakan suatu langkah untuk memaksimalkan fungsi arsip bagi kepentingan organisasi. Sebagaimana di atur dalam Undang-Undang Nomor 43 Tahun 2009 ("Undang Undang No. 43 Tentang Pokok-pokok Kearsipan," 2009) tentang system Kearsipan, telah memberikan amanat kepada Arsip Nasional Republik Indonesia (ANRI) untuk menciptakan tenaga ahli di bidang kearsipan.

Kearsipan merupakan bagian pekerjaan kantor yang sangat penting. Informasi tertulis yang tepat harus tersedia apabila diperlukan agar kantor dapat memberikan pelayanan yang 
efektif. Kearsipan sangat dibutuhkan dalam pelaksanaan administrasi karena arsip merupakan pusat ingatan bagi setiap kegiatan dalam suatu kantor. Oleh karena itu suatu kantor dalam mengelola kearsipannya harus memperhatikan sistem kearsipan yang sesuai dengan keadaan organisasinya dalam mencapai tujuannya. Efektivitas pengelolaan kearsipan pada suatu kantor dipengaruhi pula oleh pegawai yang bekerja pada unit kearsipan, sarana atau fasilitas yang dipergunakan dalam membantu pengelolaan arsip dan dana yang tersedia untuk pemeliharaan arsip tersebut.

Seiring dengan kemajuan teknologi, dunia kearsipan yang selama ini hanya berkutat pada kertas-kertas lusuh dan berbau menyengat. Kini juga tak ketinggalan telah memanfaatkan teknologi sebagai alat untuk mengolah, mengakses dan penyebaran serta pelestarian arsip. Arsip-arsip kuno yang memiliki nilai guna informasi sejarah dan mengandung keunikan yang sangat menarik sekarang telah disajikan dan diakses melalui media elektronik. Dengan memungkinkan pengaksesan yang lebih luas, diharapkan arsip merupakan barang bukti yang sekaligus mampu berbicara tentang fakta dan peristiwa sejarah dan mampu memberikan arti dan manfaat dalam kehidupan manusia. Sehingga arsip-arsip yang dulunya hanya dapat dilihat dan dibaca pada pusat-pusat arsip, kini dapat diakses secara online, dan bahkan layanannya telah mengarah pada sistem layanan otomasi.

Untuk mencapai visi dan misi Direktorat Jenderal Guru dan Tenaga Kependidikan pada Kementerian Pendidikan dan Kebudayaan, maka tusi Bagian Umum dan Kepegawaian antara lain 1) Melaksanakan urusan persuratan dan kearsipan Direktorat Jenderal; 2) Melaksanakaan penyusunan formasi dan rencana pengembangan pegawai di lingkungan Direktorat Jenderal; 3) Melaksanakan penyusunan data dan informasi kepegawaian dan administrasi penilaian prestasi/kinerja pegawai di lingkungan Direktorat Jenderal; dan 4) Melaksanakan penyimpanan dan pemeliharaan dokumen Bagian.

Dalam melaksanakan tugas dan fungsi di Bagian/Subagian tersebut terdapat isu, yaitu kesulitan untuk mendapatkan/menemukan kembali, menempatkan kembali, serta mengatur arsip sesuai dengan kebutuhan. Faktor penyebabnya adalah belum optimalnya penggunaan system kearsipan elektronik yang ada saat ini. Kondisi objektif pengelolaan arsip di lingkungan Ditjen GTK dipengaruhi oleh komponen-komponen: tugas, struktur, program, SDM dan teknologi. Komponen tersebut saling mempengaruhi. Interaksi antar komponen tersebut menunjukkan adanya identifikasi faktor-faktor permasalahan dari setiap komponen. Kondisi postur lembaga masih belum optimal apalagi mendekati ideal. Atas fakta dan realita yang dihadapi ini maka dengan semangat dan dedikasi untuk menghasilkan perubahan dan inovasi baru, mendorong penulis untuk mengembangkan lebih lanjut melalui Gagasan Proyek Perubahan.

Tujuan dari proyek perubahan ini terbagi ke dalam tiga jenis, yaitu jangka pendek, jangka menengah, dan jangka panjang. Penjabarannya adalah sebagai berikut.

1. Jangka pendek : Persiapan Perencanaan Proyek Perubahan, revisi anggaran, pembentukan tim, validasi dan verifikasi sistem yg sudah berjalan, mengupdate rancangan sistem yang tervalidasi, menguji coba rancangan sistem, bimtek sistem 
kearsipan elektronik, finalisasi sistem kearsipan elektronik, penyusunan panduan sistem dan koordinasi tahap, TOT sistem kearsipan elektronik (7 upt, 5 direktorat, 3 bagian), dan penyusunan laporan akhir proyek perubahan (11 NOVEMBER 2016).

2. Jangka menengah : Sosialisasi dan Penguatan sistem kearsipan elektronik (2017), pendampingan persiapan pelaksanaan sistem kearsipan elektronik (2017), dan penerapan sistem kearsipan di lingkungkan Ditjen GTK (2017).

3. Jangka panjang : Monitoring pelaksanaan sistem kearsipan elektronik (2018), mengevaluasi pelaksanaan sistem kearsipan elektronik (2018), mempersiapkan simpul SIKN dan JIKN (2018), dan terbentuknya SIKN dan JIKN di tingkat Kementerian (2018).

Adapun ruang lingkup dari proyek perubahan ini yang dibatasi pada :

1. Identifikasi kebutuhan pengembangan aplikasi sistem persuratan dan kearsipan yang terintegrasi.

2. Pengembangan sistem persuratan dan kersipan (Tim pengembang terdiri dari Project Manajer, Sistem Analist dan database Administrator).

3. Menyusun buku panduan (User Guide) yang meliputi: Proses intalasi aplikasi, proses persuratan dan kearsipan .

4. TOT sistem kearsipan elektronik di lingkungan Ditjen GTK.

\section{DESKRIPSI DAN ANALISIS PROYEK PERUBAHAN}

Proyek perubahan dilaksanakan dalam 3 tahapan yaitu Tahap I, Tahap II dan Tahap III. Pada masing-masing tahapan diurai menurut kegiatan-kegiatan menurut milestone. Berikut penjelasan tahapan tiap milestone:

\section{A. Pelaksanaan Tiap Tahapan Kegiatan}

Evaluasi dan monitoring dilakukan dengan pola mengikuti Tahapan (Milstone) Proyek perubahan. Pada pelaksanaan proyek perubahan ini terdiri dari 6 milestone yaitu : Mileston I, Mileston II, Mileston III, Mileston IV, Mileston V, dan Mileston VI. Berikut disampaikan uraian untuk setiap tahapannya:

\section{Persiapan Perencanaan Proyek Perubahan \\ a. Pembentukan TIM}

Pembentukan tim dilakukan pada tanggal 20 September 2016. Pembentukan tim dipimpin oleh Ketua Tim Proyek perubahan dengan melibatkan seluruh pegawai di lingkungan Bagian Umum dan kepegawaian. Pelaksanaan pembentukan tim melalui rapat yang dihadiri oleh seluruh pegawai. Mekanismenya melalui undangan dan disertai pengisian daftar hadir serta dilengkapi dengan dokumen foto. Hasil kegiatan ini adalah terbentuknya tim proyek perubahan. Hal-hal yang dibahas dalam rapat pembentukan tim antara lain:

1. Menerapkan sistem pembentukan tim tata kelola kearsipan.

2. Penyimpanan arsip menggunakan E-Kearsipan secara digital.

Manajerial, Vol. 16 No. 2 Juni 2017, Hal-223

http://ejournal.upi.edu/index.php/manajerial/ 
3. Meningkatkan sistem kearsipan dalam menyusun surat masuk dan surat keluar dengan menggabungkan sistem SAP, Aplikasi E-Office, ANRI, Konsultan arsip dan Biro Umum Kemendikbud.

Kemudian partisipasi peserta rapat antara lain mengemukakan hal-hal sebagai berikut:

1. Peserta rapat masing-masing mengemukakan tentang permasalahan pengelolaan arsip pada lembaga.

2. Peserta menghendaki adanya studi banding tentang pengelolaan arsip pada instansi pemerintahan, dalam hal ini ke ANRI.

3. Pimpinan rapat menegaskan tentang peran dan fungsi manajemen arsip untuk berbagai kepentingan baik internal maupun eksteranal.

4. Pimpinan menyampaikan tentang hakekat pengelolaan arsip secara elektronik, hal ini untuk memberikan kemudahan dan kecepatan dalam penanganan arsip.

Rapat menghasilkan keputusan pembentukan Tim Proyek Perubahan. Ada tiga tim yang dibentuk yaitu Tim 1 yaitu Tim Sosialisasi yang bertugas untuk mensosialisasikan proyek perubahan, Tim 2 yaitu Tim IT bertugas melakukan kajian tentang kearsipan elektronik dan Tim 3 yaitu elektronik, Penyusunan panduan sistem, TOT sistem kearsipan elektronik. Informasi lebih lengkap terlampir (Notula Rapat, 20 September 2016).

\section{b. Revisi Anggaran}

Langkah untuk menentukan pembiayan proyek adalah langkah merancang ulang dan melakukan revisi anggaran pembiayaan. Revisi anggaran dilakukan oleh ketua tim dengan melibatkan bagian keuangan. Pelaksanan revisi anggaran yaitu pada tanggal 21 September 2016. Tujuan revisi anggaran adalah untuk merancang biaya proyek sehingga biaya proyek sesuai dengan anggaran yang sudah diplot sebelumnya. Permasalahan yang dibahas dalam revisi anggaran antara lain:

1. Besaran anggaran yang diperlukan dalam proyek perubahan.

2. Keterbatasan dana dalam penganggaran proyek perubahan.

3. Pengalokasian anggaran sesuai dengan kebutuhan proyek.

Dalam kenyataanya penentuan anggaran perbaikan sangat rumit dilakukan karena menyangkut perhitungan dan estimasi ulang terhadap alokasi biaya yang diperlukan. Strategi yang dilakukan adalah memplot kembali berdasarkan program dan rencana kegiatan yang baru. Langkah praktis yang dilakukan adalah dengan mengkoordinasikan dengan cermat semua bagian dan kegiatan yang sudah direncanakan sebelumnya.

Hasil revisi anggaran adalah anggaran biaya proyek perubahan yang sudah disesuaikan dengan tingkat kebutuhan riil pada pelaksanaan proyek perubahan. Semoga melalui revisi anggaran kegaiatan akan memberikan dampak terhadap pelaksanaan proyek perubahan.

\section{c. Pembuatan SK}

Pembuatan SK merupakan bagian dari tahapan proyek yang bertujuan untuk menyusun, menentukan struktur dan tim pelaksana proyek sehingga proyek bisa berjalan dengan baik. Struktur pelaksana proyek yang telah terbentuk selanjutnya ditentukan pembagian tugas dan job deskripsi masing-masing. Penetapan dan pengngesahan tim 
pelaksana proyek dilakukan oleh sekretaris Direktorat Jenderal Guru dan Tenaga Kependidikan. Beberapa persoalan yang dibahas dan ditetapkan dalam tahapan penmbuatan Surat Keputusan pelaksana proyek dibahas dan dibicarakan dalam satu forum rapat. Hal-hal yang dibicarakan antara lain:

1. Biro Kepegawaian sudah menggunakan arsip secara digitalisasi online serta ada pihak ketiga dengan menggunakan ahli media.

2. Arsip yang sudah menggunakan digitalisasi juga harus mempunyai bukti fisik arsip agar memudahkan untuk menemukan arsip.

3. Arsip yang sudah 5 tahun dipindahkan ke arsip Biro Umum untuk dipindahkan ke gudang arsip di Ciketing.

4. Biro Kepegawaian sudah berjalan menggunakan metode digitalisasi untuk memproses tunjangan, SK, database pegawai baru.

5. Bagian Umum dan Kepegawaian ingin membuat tim kearsipan dengan Bagian Biro Umum Sekretariat Jenderal, ANRI juga Pustekkom.

6. Ketika ingin menggunakan aplikasi elektronik diharapkan bukti fisik atau bukti otentik untuk meyakinkan arsip asli juga stempel basah.

7. Biro Umum sudah membuatkan Tata Naskah Dinas Elektronik.

8. Bagian Umum dan Kepegawaian merencanakan membuat aplikasi elektronik untuk disosialisasikan kepada UPT di Tahun 2017.

9. Jika ingin menggunakan aplikasi E-Office maka benahi terlebih dahulu arsip agar bisa menggunakan secara digitalisasi.

10. Untuk aplikasi E-Office belum terbentuk secara sempurna karena arsip hanya direkam bukan disimpan. Jadi masih membutuhkan bukti fisik arsip.

Hal ini dimaksudkan untuk mempertegas tugas dan kewajiban anggota tim. Pelaksanaan pembuatan SK tim yaitu pada tanggal 22 September 2016. Hasil kegiatan ini adalah SK tim yang ditanda tangani oleh atasan langsung yaitu Sekretaris Jenderal Guru dan Tenaga Kependidikan. Secara kuantitatif tahapan kegiatan persiapan dan perencanaan proyek perubahan berjalan $100 \%$, artinya tahapan ini berjalan sebagaimana mestinya. Informasi lebih lengkap terlampir pada (Notula Rapat, 22 September 2016).

\section{Tahapan Pengorganisasian Proyek Perubahan}

Tahap pengorganisasian proyek perubahan adalah tahapan untuk melakukan pembagian tugas dan penjadwalan proyek. Tahapan ini terdiri dari dua kegiatan yaitu: pembuatan jadwal dan kegiatan dan pembuatan instrument monev dan pembagian tugas. Tahapan pembuatan jadwal dilaksanakan pada tanggal 23 September 2016. Tahapan pembuatan istrumen monev dilakukan seiring dengan kegiatan pengorganisasian proyek dikarenakan untuk menghemat waktu. Pembuatan instrumen dilakukan dalam rangka mempersiapkan langkah monev pada langkah atau milestone berikutnya.

Untuk memantapkan tahapan ini dilakukan rapat dan koordinasi dengan anggota tim. Pembahasan permasalahan dimaksudkan untuk mengidentifikasi dan menemukan solusi terhadap pemasalahan yang timbul selama pelaksanaan proyek. Hal-hal yang dibahas 
dalam rapat dengan tema Pengorganisasaian Proyek Perubahan antara lain penentuan langkah-langkah pembuatan aplikas Arsip-E yang diantaranya adalah:

a. Implementasi Sistem Informasi Kearsipan Dinamis (SIKD).

b. Menerapkan tata naskah dinas menurut Peraturan Menteri Kemendikbud RI Nomor 74 Tahun 2015.

c. SIKD mengikuti Peraturan Menteri Nomor 43 Tahun 2009.

d. Dalam kewajiban pencipta arsip ada beberapa penetapan kebijakan rektur bidang kearsipan, yaitu: Pola klasifikasi, Pengurusan surat, Tata Kearsipan, Aktif dan In aktif, JRA (Jadwal Retensi Arsip), Prosedur penyusunan arsip, Klasifikasi keamanan dan akses arsip. Tata cara penyerahan arsip statis, Kebijakan payung hukum tentang pedoman.

Hal lain yang dibahas tentang menyusun jadwal dan menyusun instrument monev. Hasil tahapn ini adalah jadwal kegiatan proyek dan instrument monev proyek perubahan. Lampiran hasil dan persiapan terdiri dari: undangan, daftar hadir, foto-foto kegiatan dan instrument monev. Tahapan kegiatan ini berjalan dengan baik secara kuantitatif berlangsung 100\%. Gambaran kegiatan dalam tahapan ini terekam dalam (Notula Rapat, 23 September 2016).

\section{Tahapan Koordinasi dengan Pemangku Kepentingan}

Tahapan ini terdiri dari kegiatan rapat dengan pemangku kepentingan dan Konsolidasi dengan pemangku kepentingan. Kegiatan ini bertujuan untuk menemukan titik temu antara Koordinator proyek dengan pemangku kepentingan. Rapat dengan pemangku kepentingan berlangsung pada tanggal 24 September 2016. Konsolidasi dilakukan pada tanggal 26 September 2016. Hal-hal yang dibahas pada rapat ini antara lain:

a. Membahas Implementasi Sistem Informasi Kearsipan Dinamis (SIKD).

b. Menerapkan tata naskah dinas menurut Peraturan Menteri Kemendikbud RI Nomor 74 Tahun 2015.

c. SIKD mengikuti Peraturan Menteri Nomor 43 Tahun 2009.

d. Dalam kewajiban pencipta arsip ada beberapa penetapan kebijakan rektur bidang kearsipan, yaitu: Pola klasifikasi, Pengurusan surat, Tata Kearsipan, Aktif dan Inaktif, JRA (Jadwal Retensi Arsip), Prosedur penyusunan arsip, Klasifikasi keamanan dan akses arsip, Tata cara penyerahan arsip statis, Kebijakan payung hukum tentang pedoman.

Hasil yang didapat dari tahapan ini adalah kesepakatan antara pemangku kepentingan dengan tim proyek. Tahapan kordinasi dengan pemangku kepentingan dilaksanakan dengan baik dan dilaksanakan $100 \%$. Bukti otentik pada tahapan ini terekam dalam dokumen notula (Notula Rapat, 26 September 2016).

\section{Tahapan Pelaksanaan}

Tahapan ini merupakan bagian milestone ke IV, pada tahapan ini terdiri dari: Validasi dan verifikasi sistem yg sudah berjalan, Mengupdate rancangan sistem yang tervalidasi, Menguji coba rancangan system, Bimtek sistem kearsipan elektronik, Finalisasi sistem 
kearsipan elektronik, Penyusunan Panduan arsip elektronik, TOT sistem kearsipan elektronik. Fokus permasalahan yang dibahas antara lain:

a. Meningkatkan sistem persuratan dalam menyusun surat masuk dengan menggabungkan sistem Aplikasi SAP, Aplikasi E-Office, dan Aplikasi E-Arsip.

b. Menggabungkan semua sistem aplikasi dengan tidak membuat dua kali input. Yang diharapkan data-data yang sudah di input tidak akan mudah hilang jika sudah menggabungkan dua aplikasi tersebut.

Tahapan pelaksanaan secara urut terangkum dalam jadwal pelaksanaan proyek perubahan sebagai berikut.

Tabel 1

Jadwal Pelaksanaan Proyek Perubahan

\begin{tabular}{|c|c|c|c|c|}
\hline No & Kegiatan & Pelaksanaan & Hasil & $\begin{array}{l}\text { Presentasi } \\
\text { Penyelesaian }\end{array}$ \\
\hline 1. & $\begin{array}{lr}\text { Validasi } & \text { dan } \\
\text { verifikasi } & \text { sistem } \\
\text { yg sudah berjalan }\end{array}$ & $\begin{array}{l}27 \text { September s.d } 03 \\
\text { Oktober }\end{array}$ & $\begin{array}{l}\text { Hasil } \\
\text { Validasi,Undangan,Daft } \\
\text { ar Hadir, Notulen }\end{array}$ & $100 \%$ \\
\hline 2 & $\begin{array}{l}\text { Mengupdate } \\
\text { rancangan sistem } \\
\text { yang tervalidasi }\end{array}$ & $\begin{array}{lll}4 & \text { Oktober s.d } & 07 \\
\text { Oktober } & & \end{array}$ & $\begin{array}{lr}\text { Rancangan } & \text { Sistem , } \\
\text { Undangan, } & \text { Daftar } \\
\text { hadir,Notulen } & \end{array}$ & $100 \%$ \\
\hline 3 & $\begin{array}{l}\text { Menguji coba } \\
\text { rancangan sistem }\end{array}$ & $\begin{array}{l}11 \text { Oktober s.d } 13 \\
\text { Oktober }\end{array}$ & $\begin{array}{l}\text { Hasil Uji Coba,Fotho } \\
\text { Kegiatan,Undangan, } \\
\text { Notula }\end{array}$ & $100 \%$ \\
\hline 4 & $\begin{array}{ll}\text { Bimtek sistem } \\
\text { kearsipan } \\
\text { elektronik }\end{array}$ & $\begin{array}{l}18 \text { Oktober s.d } 20 \\
\text { Oktober }\end{array}$ & $\begin{array}{lr}\text { Hasil dari } & \text { Bimtek } \\
\text { system } & \text { kearsipan } \\
\text { elektronik, Notulen, } & \text { Noto Kegiatan,Surat } \\
\text { Foto } & \text { Undangan, Daftar hadir }\end{array}$ & $100 \%$ \\
\hline 5 & $\begin{array}{ll}\text { Finalisasi } & \text { sistem } \\
\text { kearsipan } & \\
\text { elektronik } & \end{array}$ & 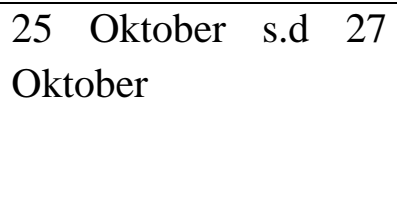 & $\begin{array}{l}\text { Sistem Kearsipan yang } \\
\text { siap digunakan, Notula, } \\
\text { Fotho Kegiatan, Daftar } \\
\text { hadir, Surat Undangan }\end{array}$ & $100 \%$ \\
\hline 6 & $\begin{array}{l}\text { Penyusunan } \\
\text { Panduan arsip } \\
\text { elektronik }\end{array}$ & $\begin{array}{l}01 \text { November s.d } 03 \\
\text { November }\end{array}$ & $\begin{array}{l}\text { Buku Panduan arsip } \\
\text { elektronik,Fotho } \\
\text { Kegiatan, } \\
\text { Undangan,Notulen, } \\
\text { Daftar Hadir }\end{array}$ & $100 \%$ \\
\hline 7 & $\begin{array}{ll}\text { TOT } & \text { sistem } \\
\text { kearsipan } & \\
\text { elektronik } & \end{array}$ & $\begin{array}{l}8 \text { November s.d } 10 \\
\text { November }\end{array}$ & $\begin{array}{l}\text { Para Trainer yang siap } \\
\text { melatih seluruh Staf } \\
\text { Arsiparis dilingkungan } \\
\text { GTK,Undangan,Daftar } \\
\text { Hadir }\end{array}$ & $100 \%$ \\
\hline
\end{tabular}




\section{Tahapan Evaluasi}

Tahapan evaluasi proyek perubahan dilaksanakan pada tanggal 10 November 2016. Tahapan ini dilaksanakan dengan tujuan untuk melihat efisiensi, efektivitas, permasalahan, dan kendala dan rintangan yang dialami selama proses pelaksanaan proyek perubahan. Hasil tahapan Evaluasi proyek Perubahan, antara lain Instrumen monitoring, analisis hasil evaluasi dan monitoring.

Evaluasi dilakukan terhadap dua hal yaitu evaluasi proses dan evaluasi hasil. Evaluasi proses yaitu mengevaluasi keseluruhan proses pelaksanaan proyek perubahan. Berdasarkan evaluasi proses sampai dengan bulan oktober presentasi keberhasilan tahapan adalah baru $50 \%$, karena untuk finalisasi evaluasi dan monitoring baru dilaksanakan pada bulan November, informasi selengkapnya ada pada bukti fisik sebagaimana dirangkum dalam notula. (Notula Rapat, 12 Oktober 2016).

Selanjutnya evaluasi juga memotret tentang kelayakan pengembangan sistem aplikasi menggunakan analisa sederhana yang merujuk pada model analisa diungkap oleh Ida Ayu Putu Ari Krisnayanti (Ayu \& Ari, 2014) Instrumen analisa diambil dari indikator sebagai berikut ; Kecepatan, Ketepatan, Keamanan, Manfaat sistem, Dampak sistem. Stakeholders memberikan persepsi tentang penerapan Arsip-E dengan memberikan skor penilaian pada kategori : Sangat Baik, Baik, Cukup dan Buruk. Hasil yang diperoleh dari persepsi responden sebagai berikut.

Tabel 2

Gambaran Variabel

\begin{tabular}{|c|c|c|c|c|c|c|c|}
\hline \multirow[b]{2}{*}{ Skor } & \multicolumn{5}{|l|}{ Indikator } & \multirow[b]{2}{*}{ Frekuensi } & \multirow[b]{2}{*}{ Persentase } \\
\hline & Kecepatan & Ketepatan & Keamanan & $\begin{array}{l}\text { Manfaat } \\
\text { Sistem }\end{array}$ & $\begin{array}{l}\text { Dampak } \\
\text { Sistem }\end{array}$ & & \\
\hline \multirow{2}{*}{ BK } & 1 & 2 & 4 & 3 & 3 & \multirow{2}{*}{13} & \multirow{2}{*}{$9 \%$} \\
\hline & $3 \%$ & $7 \%$ & $13 \%$ & $10 \%$ & $10 \%$ & & \\
\hline \multirow{2}{*}{$\mathrm{C}$} & 5 & 6 & 11 & 5 & 3 & \multirow{2}{*}{30} & \multirow{2}{*}{$20 \%$} \\
\hline & $17 \%$ & $20 \%$ & $37 \%$ & $17 \%$ & $10 \%$ & & \\
\hline \multirow{2}{*}{ B } & 18 & 15 & 9 & 15 & 16 & \multirow{2}{*}{73} & \multirow{2}{*}{$49 \%$} \\
\hline & $60 \%$ & $50 \%$ & $30 \%$ & $50 \%$ & $53 \%$ & & \\
\hline \multirow{2}{*}{ SB } & 6 & 7 & 6 & 7 & 8 & \multirow{2}{*}{34} & \multirow{2}{*}{$23 \%$} \\
\hline & $20 \%$ & $23 \%$ & $20 \%$ & $23 \%$ & $27 \%$ & & \\
\hline $\begin{array}{l}\text { Jumlah } \\
\text { Responden }\end{array}$ & 30 & 30 & 30 & 30 & 30 & 150 & $100 \%$ \\
\hline
\end{tabular}

Dari tabel di atas menjelaskan bahwa indikator Kecepatan memiliki persentase tertinggi yaitu sebesar $60 \%$ dari keseluruhan indikator lain. Selain itu gambaran variabel berada pada kategori baik dengan persentase sebesar 49\%. Hal ini menunjukkan bahwa pengembangan aplikasi Arsip-A yang digagas dalam proyek perubahan ini memberikan impact terhadap responden dalam kategori baik yaitu sebesar $49 \%$. 


\section{Tahapan Pembuatan Laporan}

Tahapan Pembuatan laporan perubahan adalah tahapan untuk menyusun laporan proyek perubahan secara keseluruhan. Tahapan ini dilaksanakan setelah selesai seminar rencana proyek dan terus bergulir sampai batas waktu yang telah ditetapkan. Dalam proyek perubahan ini laporan proyek perubahan dilaksanakan mulai tanggal 11 - 13 November 2016. Tahapan pembuatan laporan proyek perubahan ini antara lain: data data laporan, tahapan pelaporan dan laporan final yang akan diserahkan pada Pusdiklat.

Pembuatan laporan pada dasarnya adalah proses akhir dari keseluruhan tahapn proyek perubahan. Proses pembuatan laporan merupakan proses untuk menghimpun, mengkompilasi, mengolah dan menyusun semua rangkaian kegiatan menjadi satu produk atau hasil berupa laporan Proyek Perubahan. Proses ini dilakukan secara sinergis dengan melibatkan seluruh tim efektif dan komponen terkait yang terlibat dalam proyek perubahan.

\section{B. Analisis Stakeholder}

Untuk memberikan penilaian terhadap pengembangan sistem kearsipan elektronik di lingkungan Direktorat Jenderal Guru dan Tenaga Kependidikan maka harus melibatkan stakeholder di maksud di atas. Pelibatan stakeholders tersebut melalui partisipasi dalam setiap kegiatan yang dilaksanakan oleh bagian umum dan kepegawaian Setditjen GTK dalam hal ini sebagai leading sektor dari pengembangan sistem kearsipan elektronik ini.

Sejalan dengan proyek perubahan yang sedang disusun penulis mencoba menampilkan analisa stakeholder tentang pengembangan Arsip-E di lingkungan Direktorat Jenderal Guru dan Tenaga Kependidikan. Secara faktual kondisi stakeholder baik internal maupun eksternal memiliki persepsi yang beragam menanggapi keberadaan Arsip-E. Keberagaman persepsi stakeholders mengenai pengembangan Arsip-E terangkum melalui analisa stakeholder berikut.

Metode analisa merujuk pada model analisa diungkap oleh Ida Ayu Putu Ari Krisnayanti (Ayu \& Ari, 2014) dan analisa yang digunakan menggunakan SWOT analisis sebagaimana diungkap dalam (Elisa, 1999) yaitu Analisis lingkungan internal dan eksternal sering dikenal pula dengan analisis SWOT (Strength, Weakness, Opportunity and Threat). Analisis ini digunakan untuk memahami kondisi internal (kekuatan dan kelemahan) dansituasi eksternal (peluang dan hambatan), sehingga dapat diperoleh posisi suatu organisasi atau isu dalam kontek dan konten yang diemban.

\section{Penerima Manfaat}

Pihak-pihak penerima manfaat dari proyek perubahan ini, adalah sebagai berikut: 
Tabel 3

Identifikasi Stakeholder

\begin{tabular}{|l|l|l|l|}
\hline No & Stakeholder Internal & Stakeholder Eksternal & Pengaruh \\
\hline 1 & Subbagian Tata Usaha & ANRI & Positif \\
\hline 2 & Subbagian Kepegawaian & 8 Satker di Tingkat Pusat & Positif \\
\hline 3 & Subbagian Rumah Tangga & Biro Umum Kemdikbud & Positif \\
\hline 4 & & $\begin{array}{l}14 \text { UPT di lingkungan Dirjen } \\
\text { GTK }\end{array}$ & Positif \\
\hline 5 & & Pengelola Pendidikan & Positif \\
\hline
\end{tabular}

\section{Peranan dan Pengaruh}

Stakeholder (pemangku kepentingan) dipetakan dengan jelas mana yang berperan sebagai stakeholder utama (primer) dan stakeholder pendukung (sekunder). Untuk lebih jelasnya tentang peran dan pengaruh stakeholder akan dijelaskan sebagai berikut :

a. Peran Langsung dalam proyek perubahan berarti memiliki hubungan langsung dengan output dan outcome proyek perubahan.

b. Tidak langsung sebagai supporting system.

c. Stakeholder internal yang berada dalam batas kewenangan.

d. Stakeholder eksternal sebagai supporting system.

\section{Tabel 4}

Peran dan Pengaruh Stakeholder

\begin{tabular}{|c|c|c|c|c|c|c|}
\hline \multirow[b]{2}{*}{$\begin{array}{l}\mathbf{N} \\
\mathbf{O}\end{array}$} & \multirow[b]{2}{*}{$\begin{array}{l}\text { STAKEHOLDE } \\
\text { R }\end{array}$} & \multicolumn{2}{|l|}{ PERAN } & \multicolumn{3}{|c|}{ PENGARUH } \\
\hline & & $\begin{array}{l}\text { LANGSUN } \\
\text { G }\end{array}$ & $\begin{array}{l}\text { TIDAK } \\
\text { LANGSUN } \\
\text { G }\end{array}$ & $\begin{array}{l}\text { KUA } \\
\mathbf{T}\end{array}$ & $\begin{array}{l}\text { SEDAN } \\
\text { G }\end{array}$ & $\begin{array}{l}\text { LEMA } \\
\text { H }\end{array}$ \\
\hline & INTERNAL & & & & & \\
\hline 1. & $\begin{array}{l}\text { Subbag } \\
\text { Kepegawaian }\end{array}$ & $X$ & & $\mathrm{X}$ & & \\
\hline 2. & $\begin{array}{l}\text { Subbag } \\
\text { Usaha }\end{array}$ & $\mathrm{X}$ & & $\mathrm{X}$ & & \\
\hline 3. & $\begin{array}{ll}\text { Subbag } & \text { Rumah } \\
\text { tangga } & \end{array}$ & $\mathrm{X}$ & & $\mathrm{X}$ & & \\
\hline & EKSTERNAL & & & & & \\
\hline 1. & Bagian Keuangan & & $\mathrm{X}$ & $\mathrm{X}$ & & \\
\hline 2. & Bagian HTL & & $\mathrm{X}$ & & $\mathrm{X}$ & \\
\hline 3. & $\begin{array}{l}\text { Bagian } \\
\text { Perencanaan }\end{array}$ & & $\mathrm{X}$ & $\mathrm{X}$ & & \\
\hline 4. & Biro umum & $\mathrm{X}$ & & $\mathrm{X}$ & & \\
\hline
\end{tabular}




\begin{tabular}{|l|l|l|l|l|l|l|}
\hline 5. & UPT didaerah & X & & X & & \\
\hline 6. & ANRI & X & & X & & \\
\hline 7. & $\begin{array}{l}\text { Direktorat di } \\
\text { lingkungan GTK }\end{array}$ & X & X & & \\
\hline
\end{tabular}

\section{Tanggapan Stakeholder}

Gambaran mengenai stakeholder proyek perubahan terinci dalam tabel berikut :

Tabel 5

Tanggapan Stakeholder

\begin{tabular}{|l|l|l|l|l|}
\hline \multirow{2}{*}{ NO. } & \multirow{2}{*}{ PEMANGKU KEPENTINGAN } & \multicolumn{2}{|l|}{ TANGGAPAN/RESPON } \\
\cline { 4 - 5 } & & Mendukung & $\begin{array}{l}\text { Menolak } \\
\text { (resisten) }\end{array}$ & Netral \\
\hline & INTERNAL & & & \\
\hline 1. & Subbag Kepegawaian & $\mathrm{X}$ & - & - \\
\hline 2. & Subbag Tata Usaha & $\mathrm{X}$ & - & - \\
\hline 3. & Subbag Rumah tangga & & & $\mathrm{X}$ \\
\hline & EKSTERNAL & & & \\
\hline 1. & Bagian Keuangan & - & - & $\mathrm{X}$ \\
\hline 2. & Bagian HTL & $\mathrm{X}$ & - & - \\
\hline 3. & Bagian Perencanaan & - & - & $\mathrm{X}$ \\
\hline 4. & Biro umum & $\mathrm{X}$ & - & - \\
\hline 5. & UPT didaerah & - & - & $\mathrm{X}$ \\
\hline 6. & ANRI & $\mathrm{X}$ & - & - \\
\hline
\end{tabular}

4. Individu/Instansi yang Berpengaruh

Adapun instansi/individu yang berkepentingan dan memiliki pengaruh terhadap hasil akhir dari proyek perubahan, yaitu sebagai berikut.

Tabel 6

Individu/Instansi yang Berpengaruh

\begin{tabular}{|l|l|l|l|l|}
\hline NO & $\begin{array}{l}\text { STAKEHOLDERS } \\
\text { YANG } \\
\text { BERPENGARUH }\end{array}$ & $\begin{array}{l}\text { PETA } \\
\text { POSISI }\end{array}$ & $\begin{array}{l}\text { PERAN STAKE } \\
\text { HOLDER }\end{array}$ & $\begin{array}{l}\text { TINDAKAN } \\
\text { TINDAKAN }\end{array}$ \\
\hline 1. & Sekretaris Setditjen & ++++ & $\begin{array}{l}\text { Pengambil } \\
\text { Kebijakan }\end{array}$ & Mentor \\
\hline 2. & Bagian Umum & ++++ & Leader Program & $\begin{array}{l}\text { Mendesain } \\
\text { Operasional } \\
\text { pelaksanaa }\end{array}$ \\
\hline 3. & Bagian Perencanaan & +++ & Pelaksanaan Tenis & Merencanakan \\
\hline
\end{tabular}




\begin{tabular}{|l|l|l|l|l|}
\hline & & & & Anggaran \\
\hline 4. & Bagian Keuangan & ++ & $\begin{array}{l}\text { Penetepan } \\
\text { Anggaran }\end{array}$ & Menyetujui Anggaran \\
\hline 5. & Kassubag Tata Usaha & +++ & Pelaksana Tenis & $\begin{array}{l}\text { Penyipan Teknis } \\
\text { Pelaksanaan }\end{array}$ \\
\hline 6. & Kassubag Kepegawaian & +++ & Pelaksana Teknis & Penyiapan Teknis \\
\hline 7. & Kassubag Rumah Tangga & +++ & Pelaksa Teknis & $\begin{array}{l}\text { Penyiapan Sarana dan } \\
\text { Prasarana }\end{array}$ \\
\hline 8. & Biro Umum & +++ & $\begin{array}{l}\text { Pengambilan } \\
\text { Kebijakan }\end{array}$ & Regulasi \\
\hline 9. & UPT di daerah & +++ & Peserta/pengguna & Peserta \\
\hline 10. & ANRI & +++ & $\begin{array}{l}\text { Mendukung dalam } \\
\text { Regulasi }\end{array}$ & $\begin{array}{l}\text { Memberikan Saran dan } \\
\text { Masukan }\end{array}$ \\
\hline 11. & B P P & +++ & Eksukusi Program & $\begin{array}{l}\text { Mendukung dalam } \\
\text { tercapainya Kegiatan }\end{array}$ \\
\hline
\end{tabular}

Keterangan: (++++) Kuat, (+++) Cukup kuat, (++) Tidak kuat.

\section{Analisis Kekuatan Stakeholder}

a. Identifikasi Stakeholder

Identifikasi stakeholder berdasarkan kondisi struktur organisasi di lingkungan Direktorat Jenderal Guru dan Tenaga Kependidikan. Merujuk pada model analisa dari Derek Walker (Walker, Shelley, \& Bourne, 2008), dan mengadopsi dari model analisa dari Marwoto Sujud (Marwoto, 2014) maka dapat digambarkan sebagai berikut:

\section{Tabel 7}

\section{Identifikasi Stakeholder}

\begin{tabular}{|l|l|l|}
\hline & Promotors & Sekretaris Ditjen \\
& & Kepala Bagian Umum dan Kepegawaian \\
& & Subbagian Tata Usaha \\
& & Subbagian Kepegawaian \\
& Subbagian Rumah Tangga \\
\hline & Latens & $\begin{array}{l}\text { Bagian Keuangan } \\
\text { Bagian HTL } \\
\text { Bagian Perencanaan } \\
\end{array}$ \\
& Biro umum \\
\hline & Defenders & $\begin{array}{l}\text { UPT didaerah } \\
\text { ANRI }\end{array}$ \\
\hline & Apathetic & Tidak ada \\
\hline
\end{tabular}




\section{b. Kategori Stakeholder}

1) Lingkaran Stakeholder (Stakeholder Circle). Tahapan dalam membuat pemetaan dan analisis stakeholder adalah sebagai berikut:
a) Identifikasi stakeholder;
b) Prioritas (Prioritise) stakeholder;
c) Visualisasi stakeholder;
d) Pelibatan (Engage) stakeholder; dan
e) Monitor stakeholder.

2) Urutan prioritas stakeholder ditentukan berdasarkan indikator:
a) Power (kekuatan) pengaruhnya terhadap kelangsungan dan keberhasilan proyek;
b) Proximity (tingkat keterlibatan langsung) di dalam proyek;
c) Interest (kepentingan), kepentingan stakeholder dalam proyek.

\section{c. Indikator Penilaian Pengaruh Stakeholder}

Indikator penilaian pengaruh stakeholder dapat digambarkan melalui tabel di bawah ini:

\section{Tabel 8}

Indikator Penilaian Pengaruh Stakeholder

\begin{tabular}{|c|c|c|c|c|c|}
\hline Preferensi & Definisi & \multicolumn{4}{|c|}{ Definisi Operasional } \\
\hline \multirow[b]{2}{*}{$\begin{array}{l}\text { Power } \\
\text { (kekuatan } \\
\text { Pengaruh) }\end{array}$} & \multirow{2}{*}{$\begin{array}{l}\text { Kewenangan } \\
\text { formal untuk } \\
\text { mengambil } \\
\text { keputusan }\end{array}$} & 1 & 2 & 3 & 4 \\
\hline & & $\begin{array}{l}\text { Tidak } \\
\text { memiliki } \\
\text { kewenangan }\end{array}$ & $\begin{array}{l}\text { Terbatas } \\
\text { hanya pada } \\
1 \text { fungsi }\end{array}$ & $\begin{array}{l}\text { Beberapa } \\
\text { fungsi }\end{array}$ & $\begin{array}{l}\text { Penuh pada } \\
\text { semua fungsi }\end{array}$ \\
\hline $\begin{array}{l}\text { Proximity } \\
\text { (Keterlibatan) }\end{array}$ & $\begin{array}{l}\text { Keterlibatan } \\
\text { secara } \\
\text { langsung } \\
\text { pada proyek }\end{array}$ & $\begin{array}{l}\text { Tidak terlibat } \\
\text { langsung }\end{array}$ & $\begin{array}{l}\text { Pada satu } \\
\text { tahap saja }\end{array}$ & $\begin{array}{l}\text { Pada } \\
\text { beberapa } \\
\text { tahap }\end{array}$ & $\begin{array}{l}\text { Terlibat pada } \\
\text { setiap } \\
\text { tahapan }\end{array}$ \\
\hline $\begin{array}{l}\text { Interest } \\
\text { (Kepentingan) }\end{array}$ & $\begin{array}{l}\text { Kepentingan } \\
\text { terhadap } \\
\text { proyek }\end{array}$ & $\begin{array}{l}\text { Tidak } \\
\text { memiliki } \\
\text { kepentingan }\end{array}$ & $\begin{array}{l}\text { Satu } \\
\text { kepentingan }\end{array}$ & $\begin{array}{l}\text { Beberapa } \\
\text { kepentingan }\end{array}$ & $\begin{array}{l}\text { Kepentingan } \\
\text { penuh }\end{array}$ \\
\hline
\end{tabular}

Sumber: modifyng Derek Walker, et. al., 2008

\section{d. Matrik Kekuatan Pengaruh Stakeholder}

Matrik kekuatan pengaruh stakeholder dapat digambarkan melalui tabel sebagai berikut: 


\section{Tabel 9}

Matrik Kekuatan Pengaruh Stakeholder

\begin{tabular}{|l|l|l|l|l|l|}
\hline No & Stakeholder & Power & Proximity & Interest & Skor \\
\hline & INTERNAL & & & & \\
\hline 1 & Sekretaris Ditjen GTK & 4 & 4 & 4 & 12 \\
\hline 2 & $\begin{array}{l}\text { Ka Bagian Umum dan } \\
\text { Kepegawaian }\end{array}$ & 3 & 4 & 4 & 11 \\
\hline 3 & Subbagian Tata Usaha & 3 & 4 & 4 & 11 \\
\hline 4. & $\begin{array}{l}\text { Subbagian } \\
\text { Kepegawaian }\end{array}$ & 2 & 3 & 4 & 9 \\
\hline 5. & $\begin{array}{l}\text { Subbagian Rumah } \\
\text { Tangga }\end{array}$ & 2 & 3 & 4 & 9 \\
\hline & EKSTERNAL & & & & \\
\hline 1. & Bagian Keuangan & 2 & 1 & 2 & 5 \\
\hline 2. & Bagian HTL & 1 & 2 & 2 & 5 \\
\hline 3. & Bagian Perencanaan & 1 & 1 & 2 & 3 \\
\hline 4. & Biro umum & 3 & 1 & 2 & 6 \\
\hline 5 & UPT & 2 & 3 & 4 & 9 \\
\hline 6 & ANRI & 3 & 1 & 1 & 5 \\
\hline & Jumlah & 26 & 27 & 33 & 86 \\
\hline
\end{tabular}

Nilai Tertinggi $=\sum$ Indikator $\mathrm{x}$ Bobot tertinggi $=(11 \mathrm{x} 4=44)$

Nilai Terendah $=\sum$ Indikator $\mathrm{x}$ bobot terendah $=(11 \mathrm{x} 1=11)$

Rentang $=$ Nilai Tertinggi - Nilai Terendah $=(44-11=33)$

Interval

$$
=\frac{\text { Rentang }}{\text { Kelas }}=\frac{33}{4}=8,25
$$

Kategori peringkat dan strategi kerjasama dengan stakeholder berdasarkan pengaruh/minat/kepentingannya dapat diklasifikasikan sebagai berikut :

1. Apathetics (Low power, less interested people) nilai 0 simbol (- -) : Tidak punya minat/kepentingan dan tidak berpengaruh. (golongan ini di monitor terus, jangan sampai membuat bosan dengan komunikasi anda yang berlebihan). Pada posisi ini stakeholder tidak ada (kosong).

2. Latens (High Power, high interested people) nilai 19 simbol $(++)$ : Punya minat/kepentingan dan tidak berpengaruh (Cukup bekerja dg mereka agar tetap puas, tapi tidak perlu terlalu banyak sehingga mereka malah bosan dengan pesan kita)

3. Defender (Low power, High interested people) nilai 14 simbol (-+)

4. Punya minat/kepentingan dan sedikit pengaruh (Pertahankan agar orang yg masuk golongan ini tetap dijaga mendapatkan informasi, dan usahakan bicara dg mereka untuk memastikan tidak ada masalah 
5. Promoters (High Power, High Interested people) 52 simbol (- +) : Punya minat/kepentingan dan punya pengaruh (Harus melibatkan orang orang tersebut karena memiliki pengaruh besar).

\section{Kendala}

Pada proses berjalannya proyek perubahan ada beberapa kendala antara lain sebagai berikut :

1. Banyaknya beban kerja rutin yang dikerjakan oleh staf yang bersamaan dalam menghadapi daya serap anggaran sehingga banyak nya staf yang keluar daerah pada pekerjaan lain.

2. Terbatas nya sumber daya yang tersedia. Jumlah pegawai pada satuan kerja tidak sebanding dengan beban kerja yang harus dijalani, mengakibatkan terhambatnyan beberapa pekerjaan pokok.

3. Sifat program substantif yang dikerjakan bukanlah bidang keseharian yang dialami, sehingga memerlukan waktu yang cukup lama untuk bisa memahami konteksnya.

4. Keterbatasan sumber dana yang memadai untuk terus mengembangkan program perubahan ini.

5. Belum adanya regulasi yang tegas dalam mengatur program-program yang sifatnya baru.

\section{Strategi Mengatasi Kendala}

Adapun kendala atau hambatan tersebut harus dicarikan solusinya dalam pelaksanaan proyek perubahan dan harus disikapi serta dicari strateginya untuk dapat menimplementasikan proyek perubahan ini dapat berjalan dengan lancer sesuai dengan target yang telah ditentukan sesuai dengan perencanaan. Strategi yang digunakan untuk mengatasi kendala tersebut adalah sebagai berikut :

1. Diusahakan seringnya komuikasi dan koordinasi sesama staf secara persuasive;

2. Membuat jadwal khusus untuk focus mengerjakan proyek peruban diluar jam kerja;

3. Membuat Tim bayangan sebagai cadangan jika Tim yang sudah ada mengalami gangguan.

4. Banyaknya beban kerja rutin yang dikerjakan oleh staf yang bersamaan dalam menghadapi daya serap anggaran sehingga banyak nya staf yang keluar daerah pada pekerjaan lain, maka strategi yang diterapkan adalah dengan pembagian tugas dan penjadwalan secara teratur.

5. Terbatasnya sumber daya yang tersedia. Jumlah pegawai pada satuan kerja tidak sebanding dengan beban kerja yang harus dijalani, mengakibatkan terhambatnyan beberapa pekerjaan pokok strategi yang dilakukan dengan cara menentukan skala prioritas dan mengangkat tim teknis untuk menyelesaikan bagian pekerjaan.

6. Sifat program substantif yang dikerjakan bukanlah bidang keseharian yang dialami, sehingga memerlukan waktu yang cukup lama untuk bisa memahami konteksnya, strategi yang dilakukan adalah melalui pelatihan dan pemantapan bidang substantif yang masih kurang. 
7. Keterbatasan sumber dana yang memadai untuk terus mengembangkan program perubahan ini, Strategi yang dilakukan adalah dengan merelokasikan anggaran yang tidak terserap.

8. Belum adanya regulasi yang tegas dalam mengatur program-program yang sifatnya baru, strateginya adalah membuat aturan dan membuat keputusan untuk menetapkan aturan-aturan yang diperlukan.

\section{E. Capaian Kegiatan}

Capaian kegiatan dari proyek perubahan milestone ini dilaksanakan pada tanggal 20 September s.d. tanggal 13 November 2016. Target capaian kinerja proyek perubahan ini secara rinci dapat dilihat sebagai berikut:

1. Terjadi peningkatan pemahaman stakeholder/pemangku kepentingan terhadap pentingnya Aplikasi Arsip-E.

2. Peningkatan pemahaman stake holder atau pemangku kepentingan dalam hal Aplikasi Arsip-E untuk penanganan masalah kearsipan di setiap lembaga.

3. Terjadi peningkatan pemahaman pentingnya mengelola arsip elektronik berbasis internet.

4. Target capaian proyek perubahan tentang kearsipan elektronik Arsip (Arsip-E) akan ditindaklanjuti dengan program-program kegiatan lainnya.

\section{KESIMPULAN}

Penanganan arsip pada instansi pada kenyataanya belum optimal, disebabkan oleh keterbatasan pada aspek SDM, sarana dan prasarana, kebijakan pimpinan instansi dan dampak perkembangan teknologi informasi dan komunikasi.

Tuntutan kemajuan dan perkembangan teknologi, informasi dan komunikasi menuntut pemenuhan solusi terhadap persoalan pengelolaan arsip. Terobosan melalui inovasi dalam bidang teknologi informasi mendorong untuk menciptakan media untuk mengelola arsip secara modern, yaitu memadukan sistem kearsipan konvensional dengan kemajuan teknologi. Pengembangan Aplikasi Arsip-E adalah salah satu tawaran solusi untuk mengatasi permasalahan dalam pengelolaan arsip.

Berbagai analisis dilakukan untuk mencari solusi terhadap persoalan pengelolaan arsip, dengan tujuan untuk menghasilkan satu sistem pengelolaan arsip secara modern dengan pendekatan teknologi informasi dan komunikasi. Pengembangan Arsip-E adalah solusinya. Analisis dengan pendekatan konsep Levit telah memetakan skala prioritas pengembangan sistem kearsipan elektronik. Pendekatan model Derek telah menghasilkan analisis stakeholder dimana stakeholder internal dan eksternal memiliki dukungan yang sangat tinggi terhadap pengembangan Arsip-E. Evalusi Usability Heuristics dari Nielsen telah menghasilkan kelayakan dan visibilitas aplikasi yang dikembangkan. Analisis usability heuristic menyimpulkan bahwa aplikasi Arsip-E memiliki visibilitas dengan kategori baik, artinya memiliki keterbacaan oleh pengguna dengan baik.

Secara umum proses pelaksanaan kegiatan proyek perubahan berjalan dengan baik, lancar dan sesuai dengan perencanaan. Hasil pelaksanaan antara lain: 
1. Tersedianya Sistem kearsipan elektronik menjamin tersedianya arsip yang autentik dan terpercaya sebagai alat bukti sah khususnya dibidang kepegawaian dan keuangan serta menjamin terwujudnya pengelolaan arsip yang handal dan pemanfaatnanya sesuai dengan ketentuan perundang undangan

2. Keberadaan Sistem Kearsipan elektronik ini maka akan terciptanya pegawai yang terampil dan profesioanl dalam pengelolaan kearsipan dan sangat membantu bagi fungsional tertentu yaitu Arsiparis

3. Adanya system kerasipan elektronik maka dengan mudahnya serta cepat dalam hal ini staf atau pimpinan pencarian arsip yang dibutuhkan sewakt waktu.

4. Tersedianya system kearsipan elektronik dapat mendinamiskan penyelengagaraan kearsipan di suatu unit kerja sebagai suatu system yang koprehensip dan terpadu

5. Tersedianya system kearsipan elektronik dapat menjamin kerahasian serta keamanan arsip itu sendiri.

\section{DAFTAR PUSTAKA}

Notula Rapat. (12 Oktober 2016). Uji Coba Rancangan Sistem untuk Peningkatan Tata Kelola E-Kearsipan Direktorat Jenderal Guru dan Tenaga Kependidikan.

Notula Rapat. (20 September 2016). Pembentukan Tim Tata Kelola Kearsipan Direktorat Jenderal Guru dan Tenaga Kependidikan. Jakarta.

Notula Rapat. (2016). Pembentukan Tim Tata Kelola Kearsipan Direktorat Jenderal Guru dan Tenaga Kependidikan. Jakarta.

Notula Rapat. (22 September 2016). Pembuatan Jadwal Kegiatan, Pembagian Kerja dan Pembuatan Instrumen Monev Tata Kelola E-Kearsipan Direktorat Jenderal Guru dan Tenaga Kependidikan.

Notula Rapat. (23 September 2016). Koordinasi dengan Pemangku kepentingan untuk Peningkatan Tata Kelola E-Kearsipan Direktorat Jenderal Guru dan Tenaga Kependidikan.

Notula Rapat. (26 September 2016). Koordinasi dengan Pemangku kepentingan untuk Peningkatan Tata Kelola E-Kearsipan Direktorat Jenderal Guru dan Tenaga Kependidikan.

Notula Rapat. (27 September). Validasi dan Verifikasi sistem yang sudah berjalan (EOffice) untuk peningkatan Tata Kelola Kearsipan Direktorat Jenderal Guru dan Tenaga Kependidikan.

Ayu, I., \& Ari, P. (2014). Analisis Persepsi Stakeholder Internal Dan Eksternal Terhadap Transparansi Dan Akuntabilitas Laporan Keuangan Pengelolaan Dana BOS di SMP Negeri 1 Banjar Tahun 2013.

Effendhie, M. (1993). ASPEK TEORITIS DAN LEGALITAS, (3), 47-52.

Manajerial, Vol. 16 No. 2 Juni 2017, Hal-237

http://ejournal.upi.edu/index.php/manajerial/ 
Elisa. (1999). analisis lingkungan internal dan eksternal. Retrieved from http://webcache.googleusercontent.com/search?q=cache:nZbXxtspsk4J:elisa.ugm .ac.id/user/archive/download/24062/b69c27dcc82cc712e3387f9fe533cbfd+\&cd= $3 \& \mathrm{hl}=\mathrm{id} \& \mathrm{ct}=\mathrm{clnk} \& \mathrm{gl}=\mathrm{id}$

Falletta, S. V, \& Ed, D. (2005). Organizational Diagnostic Models : A Review \& Synthesis White Paper, 1-43.

Ismael, I. (2013). KETERLAMBATAN PROYEK KONSTRUKSI GEDUNG FAKTOR PENYEBAB DAN TINDAKAN PENCEGAHANNYA Oleh. Februari Jurnal Momentum, 14(1), 46-56.

Kemendikbud. (2015). Permendikbud No. 11 tahun 2015, Tentang Organisasi dan Tata Kerja Kementerian Pendidikan dan Kebudayaan.

Latif, F., \& Pratama, A. W. (2008). Perancangan sistem informasi manajemen arsip elektronik (e-arsip) berbasis microsoft access pada pt. hi-test. Prodi Administrasi Bisnis Terapan Poltek Negeri Batam.

Marwoto, S. (2014). Laporan proyek perubahan peningkatan pemahaman masyarakat terhadap pentingnya paud di wilayah kerja upt pendidikan kecamatan bojong.

Walker, D., Shelley, A., \& Bourne, L. (2008). Influence , Stakeholder Mapping and Visualisation Abstract :, 1-19.

Sutirman. (2015). Manajemen Arsip Elektronik. Universitas Negeri Yogyakarta, 1-8.

Undang Undang No.11 tahun 2008, tentang Informasi dan Transaksi Elektronik. (2008).

Undang Undang No. 14 tahun 2008 tentang Keterbukaan Informasi Publik. (2008).

Undang Undang No. 43 Tentang Pokok-pokok Kearsipan. (2009). 